\author{
Czesław Machelski \\ prof. dr hab. inż. \\ Politechnika Wrocławska \\ Wydział Budownictwa Lądowego i Wodnego \\ Katedra Dróg, Mostów, Kolei i Lotnisk \\ czeslaw.machelski@pwr.edu.pl
}

DOI: 10.35117/A_ENG_21_01_03

\title{
Characteristic changes the bending moments in shell of soil-steel structures
}

\begin{abstract}
There are two structural subsystems in the soil-steel structure model: a flexible corrugated steel shell and a soil backfill. A characteristic feature of the analyzed structures, in contrast to classic bridges, e.g. brick ones, is a very large influence of the soil backfill on internal forces and deformation of the steel shell. Usually, during construction, the stresses in the shell are many times greater than those arising from the operational loads. In the paper analyzes changes bending moments in the steel shell during the operation of the object as a result of deformation occurring during the construction phase. The test results indicate that the bending moments of the steel structure depends on the geometry of the bridge but with a large influence of the technology of the backfill process. The paper presents an algorithm for estimating shell shape changes based on displacements occurring in the construction phase. The examples show a favorable reduction of bending moments in shells with a regular arc. An unfavorable geometry for box-shaped shells has been demonstrated. The results of the analysis presented in the paper may be the basis for the measurement methodology in the monitoring of soil-steel structure bridges, both during construction and in the operational phase.
\end{abstract}

Keywords: Soil-steel structures; Corrugated sheets; Bending moments; forecast

\section{Bridge facilities monitoring}

Bridge structures with large spans (lengths) and important communication are subject to monitoring both during construction and during their operation. An example may be the observations of suspension bridges [2]. Particularly, research concerns prototype construction technologies. A good example are concrete overhang bridges [9]. Fig. 1 shows the results of monitoring in the form of a change of the grade line of a bridge built with the use of this technology. The presented diagrams show a very fast increase in deflections immediately after shorting the span supports and the lack of stabilization during the lifetime of the facility. The research $[6,9]$ analyzed the effects of rheological processes in concrete and prestressing steel [9]. Numerous studies show a very large influence of construction technology on the operation of the exploited structure [6]. Based on the deflections, the change in the creep function and bending moments are estimated. 


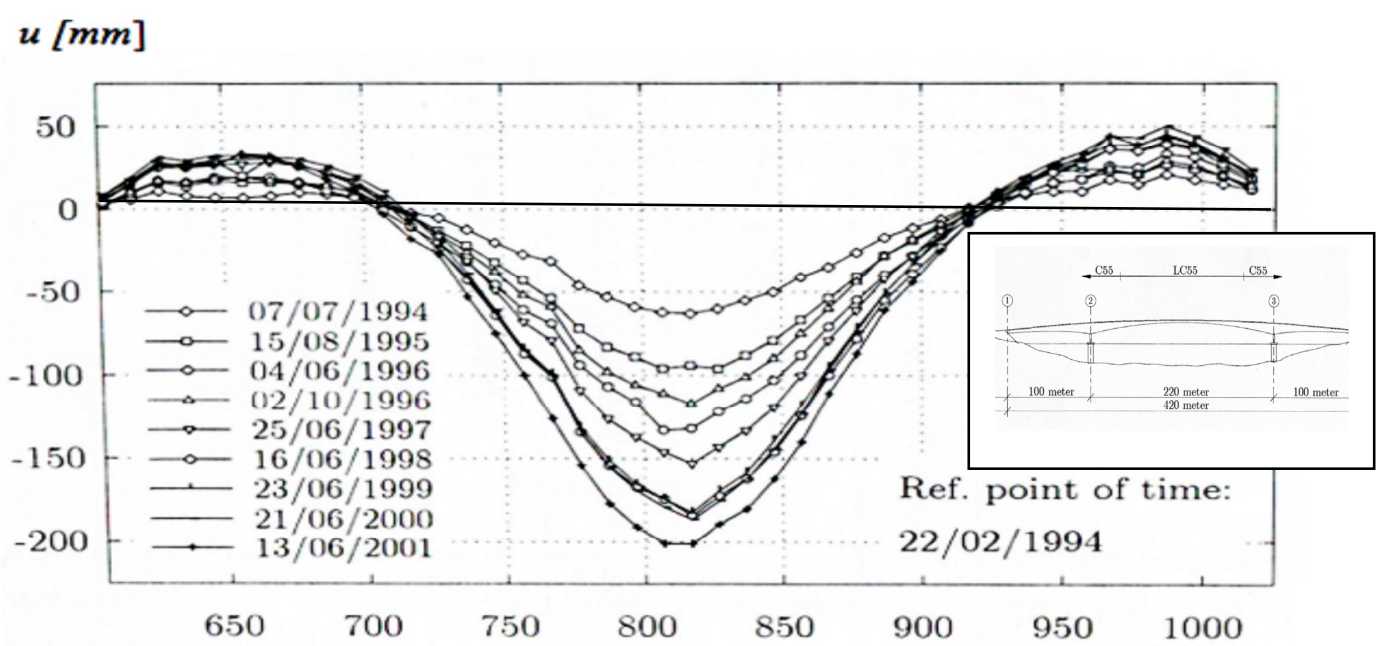

1. Changes of the grade line of the Støvset bridge spans during its operation [9]

Soil-shell bridge structures are monitored more often during their construction than during their use. This is due to the fact that during the laying of the backfill, internal forces and deformation occur much greater than under the operational loads [4]. Fig. 2 shows one of the results of continuous monitoring of a selected facility over Piekielnica [8]. The deformation of this shell differs significantly from that in other objects. Geodetic measurements of the coordinates of points on the coating were carried out on the inner surface of the corrugated sheet from the beginning of construction, i.e. from 1999.

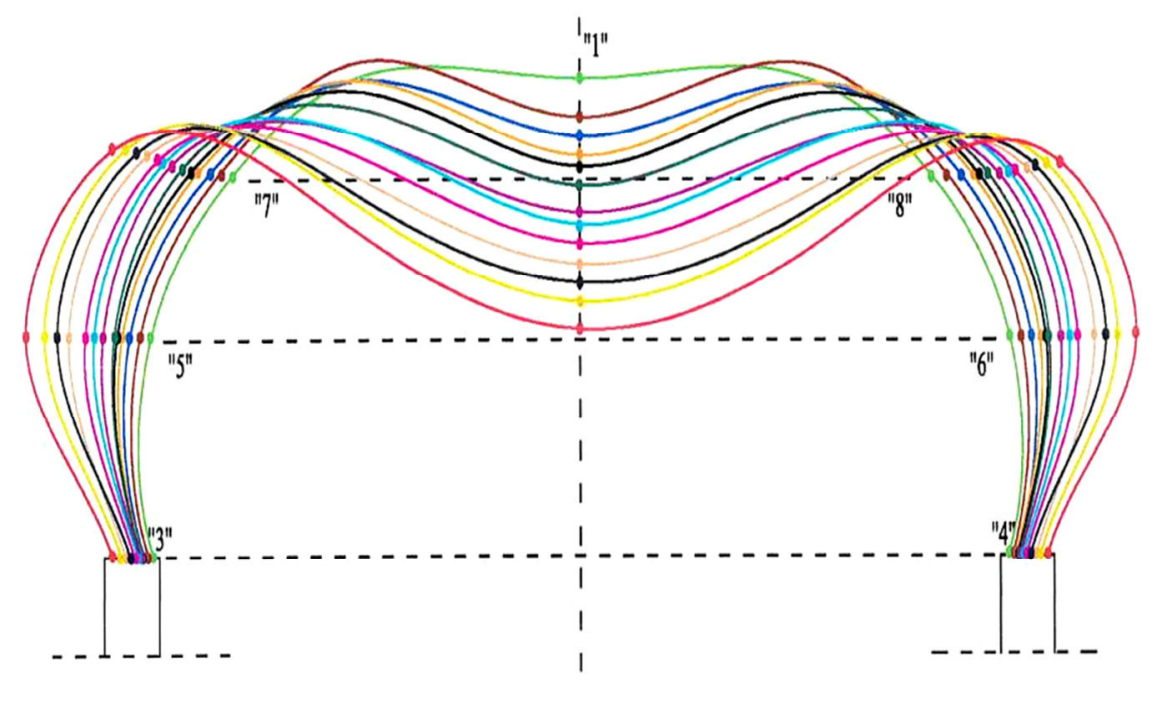

2. Changes in the shape of the object's shell over Piekielnica [8]

The comparison of the displacement diagrams presented in both figures shows their great similarity. The description of the behavior of these structures may be similar, however, the physical properties of both materials (concrete and soil) are completely different. The common feature of these effects is a very large influence of the construction phase on the operation of the structure during its operation [4, 6]. Since 1998, the Rubierz railway ground and coating facility has been monitored as the first in Poland [7]. It is subject to further observation. Earlier studies of soil-shell objects included geotechnical phenomena. The analyzes were 
focused on changes in soil pressures in soil and shell structures with the use of pressure gauges [10].

Research on the behavior of soil-shell objects during their operation is carried out sporadically. The paper presents the methodology of carrying out measurements useful for the observation of changes in the shell geometry during the construction and operation of the object. Geodetic measurements are sufficient for the implementation of such a procedure [4].

\section{Shell geometry groups}

For the determination of the shell geometry group of soil-shell objects made of corrugated sheets, the circumferential direction is distinguished as a line along with the wave of the sheet. This is the main direction of the shell operation, included in the static scheme, as shown in Fig. 3. Due to the characteristic changes in the shell deflection in the key, the soil-shell structures are divided into three groups [5]: open arched (A) and box-shaped (B), and closed (C). Fig. 3 shows changes in the spanner deflection $w$, together with an increase in the thickness of the backfill layer $z_{\mathrm{g}}$ (in proportion to the height of the shell $h$ ). In the C shell initially, there is a negative value $\mathrm{w}$, but later the graph is similar in shape to the A shell. In the further part of the work, the $\mathrm{C}$ type shell is treated as belonging to the A group.

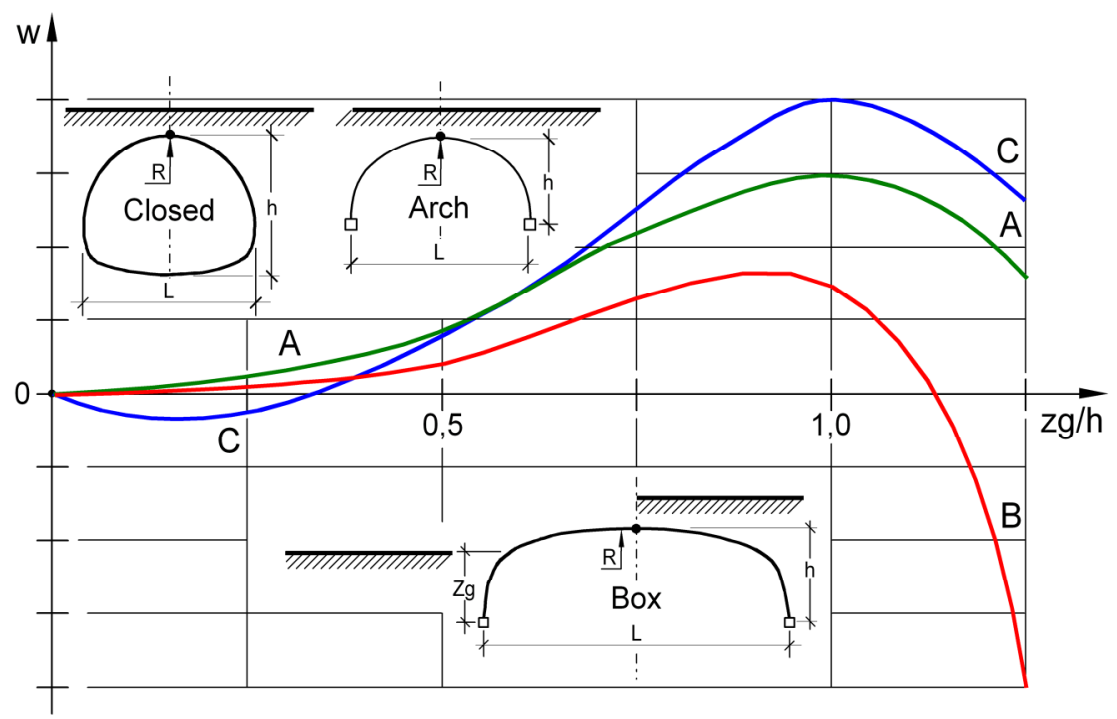

3. Characteristic changes in deflection of the shell key during soil backfill laying

A common feature of the shells circumferential band geometry (cross-section) is the shape of the upper part with a radius of curvature $R$. This feature is used in the work, assuming that the remaining part of the cross-section in these shells can be any. In each of these cases, there is a different course of the function $w\left(\mathrm{z}_{\mathrm{g}}\right)$ depending on the level of backfill calculated from the foundation as $\mathrm{zg}$. The forms of such functions are presented in many works listed in [4].

The deformation of the circumferential band of the coating defined by displacement $w$ and $u$ can be accounted for in the change in the curvature of the perimeter strip of the corrugated sheet. For this purpose, the change of the shape of the coating is used, as in Fig. 4a, and geodetic measurements. The shell deforms to a design shape in the form of a radius segment of a circle $R$ - changing to value $R_{\mathrm{uw}}$. Based on the initial value $R_{\mathrm{o}}$ (after installation) the change in curvature of the circumferential band is determined as in the formula

$$
\kappa_{u w}=\frac{R_{o}-R_{u w}}{R_{o} \cdot R_{u w}}
$$


When using strain gauge measurements, the unit strains on the edge of the upper and lower waves are determined as shown in Fig. 4b. Assuming the principle of flat sections, the change in curvature is obtained from the equation

$$
\kappa_{\varepsilon}=\frac{\varepsilon_{g}-\varepsilon_{D}}{f}
$$

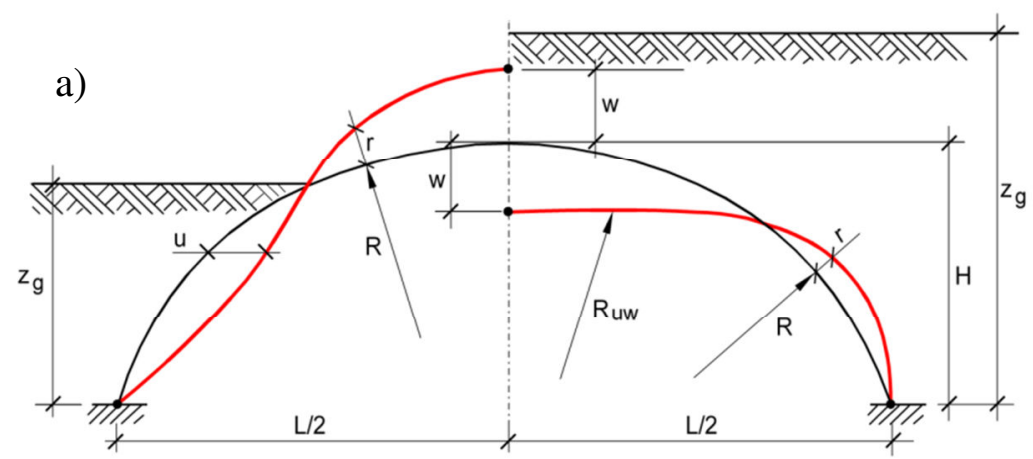

b)

4. Diagram of the circumferential strip of the shell

a) the scheme of the arc-shaped shell during construction

b) unit deformation measurement system

Usually, the shell point analyzed is the key, as it is the highest in the cross-section, as in Fig. 3. In this cross-section, the greatest changes occur in curvature. Geometric parameters of the shell: $L, H, R$ are the main dimensions of the cross-section, as in Figure 4a. This drawing shows a characteristic change in the shape of the shell during construction. The study analyzes the deformation of the circumferential band during the operation of the object but without the participation of moving loads.

\section{Curvature changes as a function of time}

The study analyzes the change in curvature at a selected point in the circumferential band as a function of time. The following characteristic moments from the construction and operation period of the facility are distinguished:

- $\mathrm{t}_{\mathrm{o}}$ as the moment of completing the shell installation;

- $\mathrm{t}_{\mathrm{k}}$ when the greatest uplift occurs in the shell key $w$;

- $\mathrm{t}_{\mathrm{p}}$ is the time of construction completion;

- $t_{\mathrm{e}}$ the situation during the operation of the facility is analyzed.

Fig. 5 shows the curvature changes diagrams in the analyzed types of shells: A and B. Additionally, a shell with intermediate properties, marked as AB, was introduced.

The changes in curvature are included in the work in the equation

$$
\kappa(t)=f(t)\left(\kappa_{k}+\kappa_{p}\right)-\kappa_{k} \quad,
$$

using a deformation function that depends on the time $\mathrm{f}(\mathrm{t})$ and two parameters $\kappa_{\mathrm{k}}=\kappa\left(\mathrm{t}_{\mathrm{k}}\right)$ and $\kappa_{p}=\kappa\left(t_{p}\right)$. The curvature change function is continuous with the characteristic points shown in Fig. 5. The assumption of shell deformation and formula (1) shows that $\kappa_{\mathrm{o}}=\kappa\left(\mathrm{t}_{\mathrm{o}}\right)=0$. 


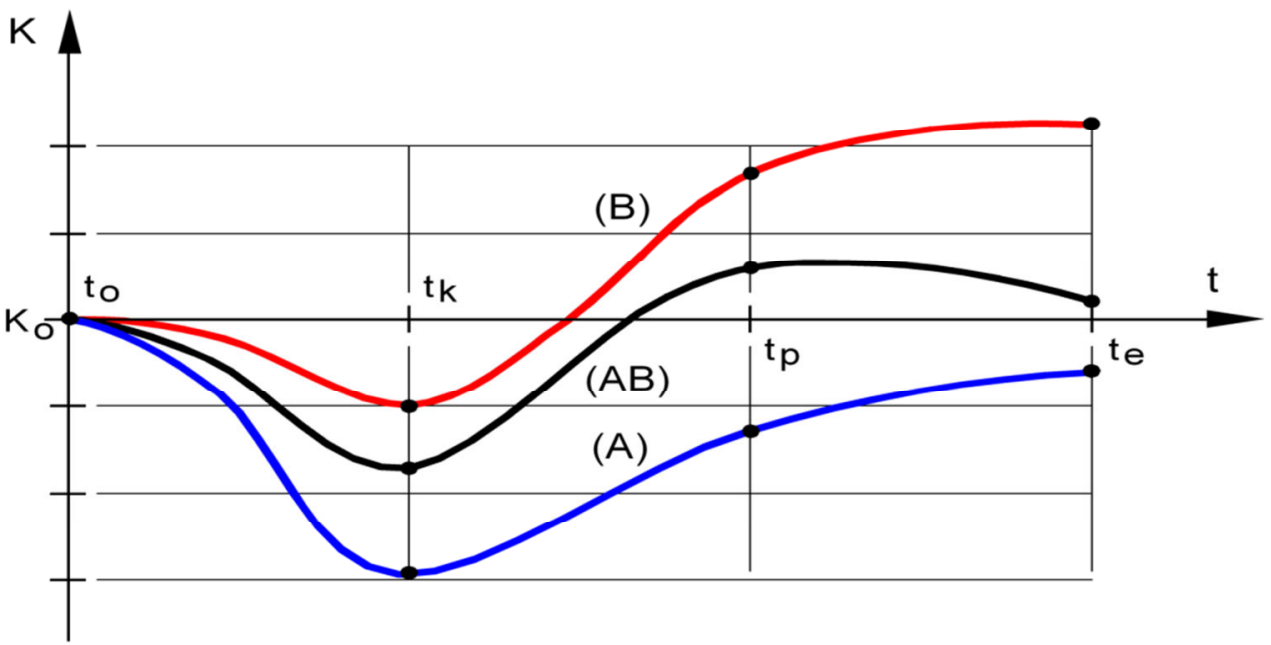

5. Changes in the shell curvature during construction and operation

\section{Deformation formula}

The deformation function can be obtained directly from formula (3)

$$
f(t)=\frac{\kappa_{k}+\kappa(t)}{\kappa_{k}+\kappa_{p}}
$$

A special feature $f(\mathrm{t})$ is standardized at the time of construction completion and the beginning of operation $t_{\mathrm{p}}$. Then

$$
f\left(t_{p}\right)=f_{p}=1 .
$$

At the remaining characteristic points, $\mathrm{f}(\mathrm{t})$ takes the following values:

$1 . t=t_{\mathrm{o}}$

$$
f\left(t_{o}\right)=f_{o}=\frac{\kappa_{k}}{\kappa_{k}+\kappa_{p}} .
$$

$2 . t=t_{\mathrm{k}}$

$$
f\left(t_{k}\right)=f_{k}=2 f_{o} \quad .
$$

$3 . t=t_{\mathrm{e}}$

$$
f\left(t_{e}\right)=f_{e}=\frac{\kappa_{k}+\kappa_{e}}{\kappa_{k}+\kappa_{p}}=f_{o}\left(1+\frac{\kappa_{e}}{\kappa_{k}}\right) .
$$

In general terms, the deformation function can be related to the initial value $f_{\mathrm{o}}$ but determined after construction as in the formula of the form

$$
f(t)=f_{o}\left(1+\frac{\kappa(t)}{\kappa_{k}}\right) .
$$

The deformation function $\mathrm{f}(\mathrm{t})$ is determined based on measurements on the object with the use of curvature changes and formulas (1) or (2). The shape of the graph is influenced by the geometry of the shell, as well as the technology of laying the backfill: the method of its compaction, the use of soil reinforcement as well as the working break periods [4].

Characteristic figures are presented in Fig. $6 f(\mathrm{t})$ for the three types of shell geometry $\mathrm{A}, \mathrm{AB}$, and $\mathrm{B}$. The shape of the function results from the following curvature relations that arose during the construction:

4. A type $(\operatorname{arch})$ when $\kappa_{\mathrm{k}}>\kappa_{\mathrm{p}}>0$;

5. AB type when $\kappa_{\mathrm{k}}>-\kappa_{\mathrm{p}}$ and $\kappa_{\mathrm{p}}<0$;

6. B type $($ box $)$ when $\kappa_{\mathrm{k}}<-\kappa_{\mathrm{p}}$ and $\kappa_{\mathrm{p}}<0$. 


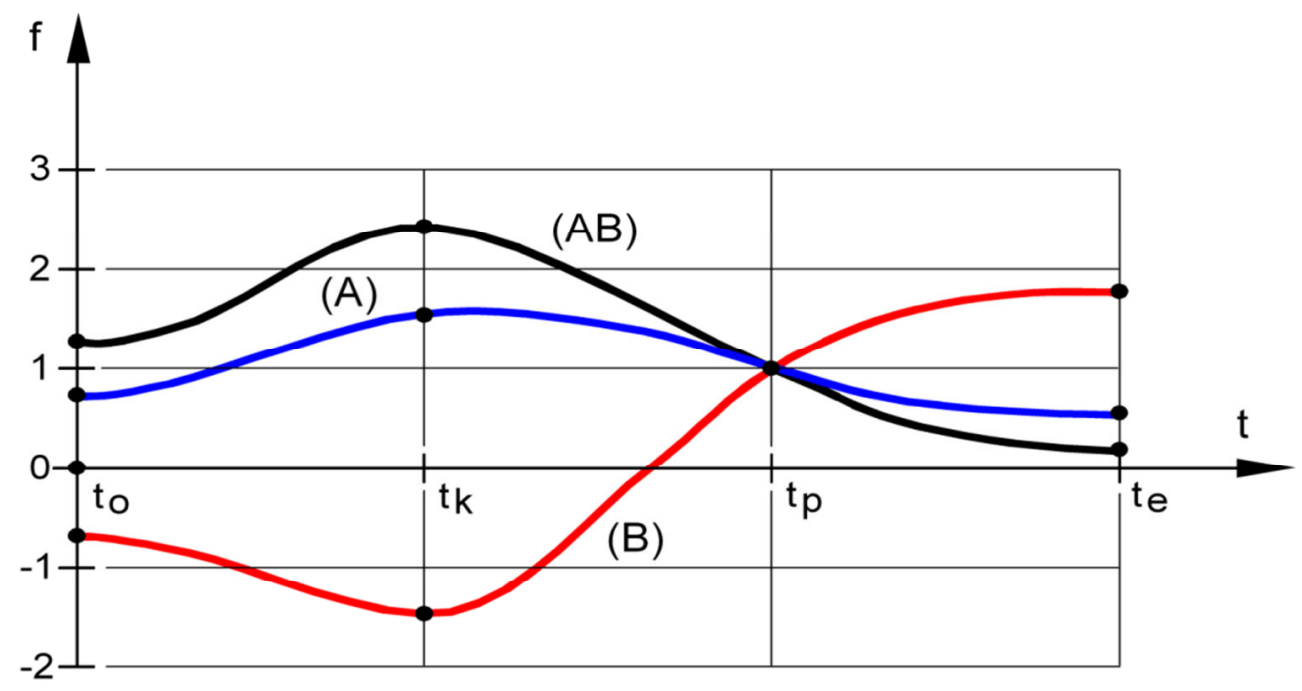

6. Characteristic forms of the deformation function

Thus, based on the value relation $\kappa_{\mathrm{p}}$ in reference to $\kappa_{\mathrm{k}}$ the shell qualifies as type A (or $\mathrm{AB}$ ) and $\mathrm{B}$. The comparison of $\mathrm{f}(\mathrm{t})$ diagrams for arc and box shells shows symmetry with respect to the time axis, but only in terms of $t_{o}<t<t_{\mathrm{k}}$. In the next time interval, the values of $\mathrm{f}(\mathrm{t})$ are reduced in the coatings $A$, in the case of box-shaped shells the function $\mathrm{f}(\mathrm{t})$ may not be stabilized. This is a significant difference in assessing the safety of both types of shells. The coatings with $\mathrm{AB}$ characteristics are unique. It is important that the qualification is also influenced by the technology of laying the backfill. Of course, the smooth diagrams presented in Fig. 6 are in practice subject to disturbances, in particular, the formation of discontinuities during the working breaks $[1,4]$.

\section{Box-shaped shell}

The most commonly used coatings in bridge engineering are A and C type shells. B-type shells are built in railway facilities. Such an example of an object was realized in Lidköping (Sweden) with the assumption that it would be the subject of detailed research [9]. The work uses the results of strain gauge measurements, which have been converted into a function of bending moments, as in Fig. 7 (supplemented with deflections in the shell key). In this case, the relationship is used to obtain the curvature change

$$
\kappa=E I \cdot M\left(z_{g}\right)
$$

where $E I / a=4,95 \mathrm{MNm}^{2} / \mathrm{m}$, as in the case of sheet metal SC $380 \times 140 \times 7$. Thus, the function $\kappa(\mathrm{t})$ may be similar to $\kappa\left(\mathrm{z}_{\mathrm{g}}\right)$ and $M\left(\mathrm{z}_{\mathrm{g}}\right)$ when the increase in backfill thickness is proportional to the passage of time $t$. 


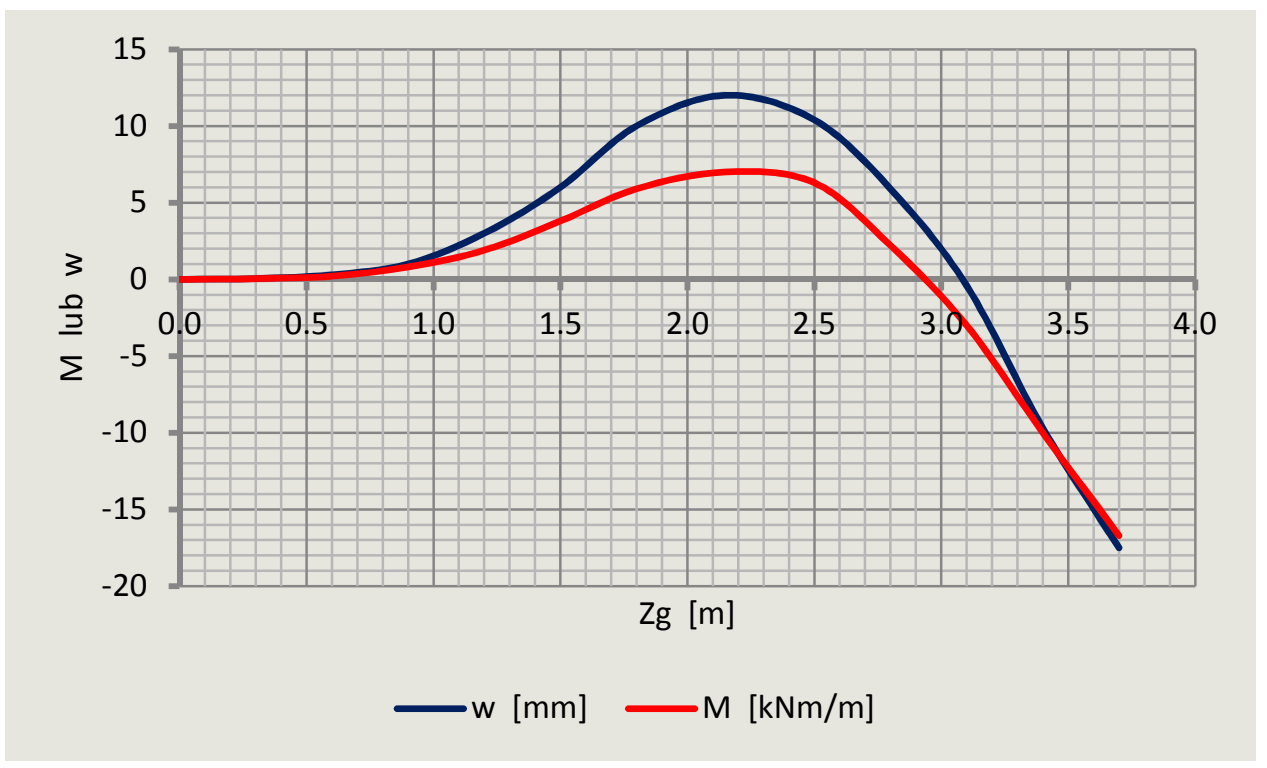

7. Change of deflection and bending moment in the shell key

\section{Arc-shaped shell}

The functions $\mathrm{f}(\mathrm{t})$ in arc-shaped shells are treated as models (the most common) in soil-shell structures. In the case of box-shaped shells, the function $\mathrm{f}(\mathrm{t})$ is not reduced during operation. Fig. 8 shows the results of the research on the specific coating of the object over Piekielnica [8]. The shell is classified as the arc (type A) based on its shape, in this case, it behaves like type B, i.e. box geometry. Characteristic values of $\mathrm{f}(\mathrm{t})$ are presented in Tab. 1 .

Tab. 1 compares the geometric parameters of three examples of objects. Shamal Bridge near Dubai, with the largest span in the world, was adopted as the A structure.

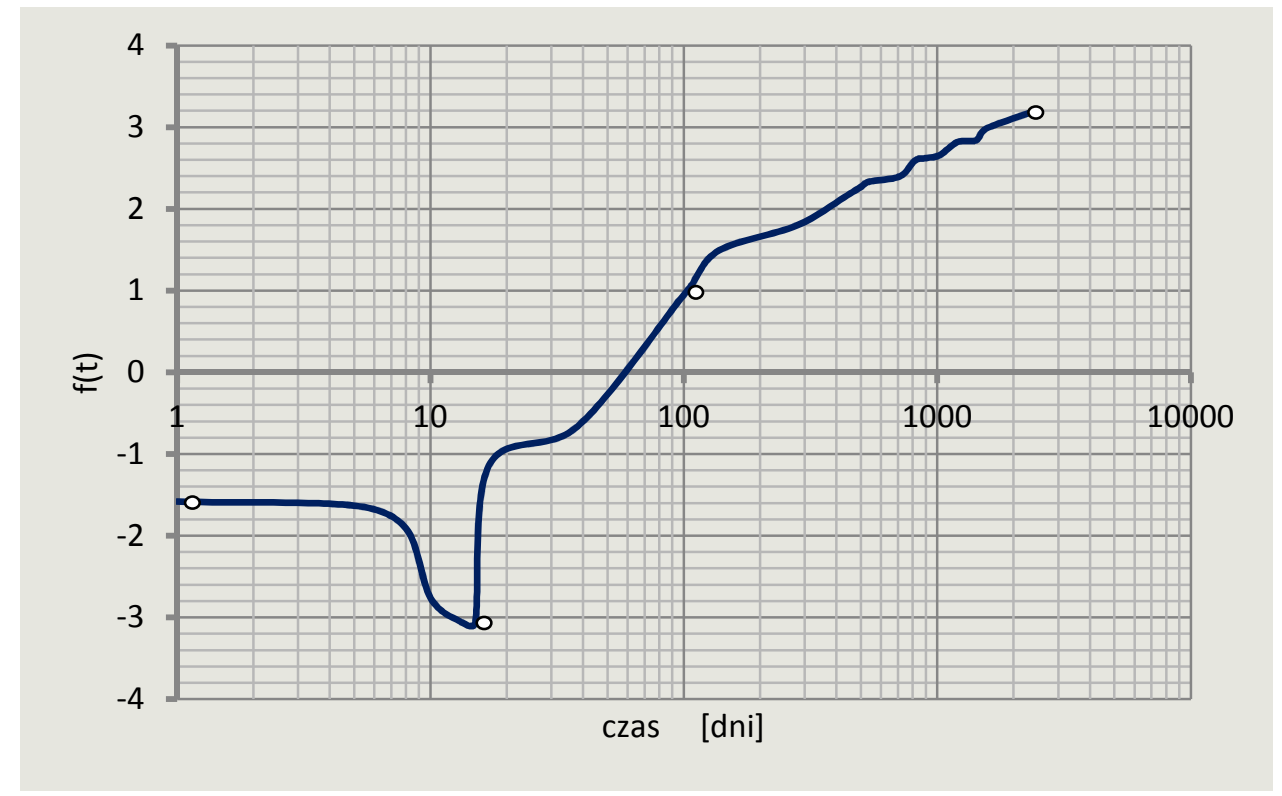

8. Function $\mathrm{f}(\mathrm{t})$ of the object over Piekielnica 
Tab. 1. Geometric parameters of shells

\begin{tabular}{|c|c|c|c|c|c|c|c|}
\hline \multirow{2}{*}{ Object } & \multicolumn{3}{|c|}{ Shell dimensions [m] } & \multicolumn{3}{|c|}{ Deformation function values } \\
\cline { 2 - 6 } & $L$ & $H$ & $R$ & $f_{o}$ & $f_{k}$ & $f_{p}$ & $f_{e}$ \\
\hline Dubai & 32,60 & 9,570 & 29,68 & 0,759 & 1,518 & 1 & - \\
\hline Piekielnica & 13,46 & 5,004 & 9,930 & $-1,581$ & $-3,162$ & & 3,185 \\
\hline Lidköping & 8,085 & 2,440 & 8,820 & $-0,734$ & $-1,468$ & & - \\
\hline
\end{tabular}

\section{Changes in bending moments}

The deformation function $\mathrm{f}(\mathrm{t})$ is useful for tracking the change in bending moments during the operation of the object, as in the formula

$$
M(t)=E I\left\lfloor f(t)\left(\kappa_{k}+\kappa_{p}\right)-\kappa_{k}\right\rfloor \quad .
$$

as in Fig. 6. When the object is classified as group A, the moment values will be reduced. This is positive for the shell because it will be subjected to compression to a greater extent as in the natural arcuate geometry. Objects of group B show a tendency to increase $M$ during operation. They may be larger than during construction at the time $\mathrm{t}_{\mathrm{p}}$. This is confirmed by the example of the $f(t)$ diagram of the object over Piekielnica [8], presented in Fig. 8. In general, the function $\mathrm{f}(\mathrm{t})$ is used to determine the convergence of bending moments during the operation of the object - it is the basis for the decision to monitor the object.

If strain gauges are used and the curvature $\kappa_{\varepsilon}$ change hence obtained as in formula (2), the change in the radius of curvature can be followed $R_{\mathrm{uw}}$, using the formula (1). Then the changes in curvature are assumed to be consistent $\kappa_{\mathrm{uw}}=\kappa_{\varepsilon}$ and hence the radius of curvature is obtained after shell deformation as

$$
R(t)=\frac{R_{o}}{R_{o} \cdot \kappa_{\mathcal{E}}+1}
$$

However, one should remember the difference in the method of determining the radius of curvature $R_{\mathrm{uw}}$ it is determined based on geodetic measurements and displacements $u$ and $w$, the perimeter section, as in Fig. $4 \mathrm{a}$. Whereas $R(\mathrm{t})$ is determined in the analyzed cross-section from geometrical relationships, as in Fig. $\mathbf{4 b}$. The justification for the correctness of such a solution is given in the paper [3].

Using the principle given earlier on the basis o $R_{\mathrm{uw}}$ you can also track changes in bending moments as in the formula

$$
M(t)=E I \frac{R_{o}-R_{u w}}{R_{o} \cdot R_{u w}}
$$

\section{Summary}

During the construction of soil-shell structures, internal forces and deformations in the shell occur much greater than under operational loads. Hence, the monitoring of these facilities is usually limited to the construction phase, in addition to facilities with new types of sheets and atypical geometry. During the operation of the facilities, measurements are performed sporadically. Exceptionally, the first soil-shell facility built in Poland, Rubierz [7] is subject to random and further observation.

The paper presents an algorithm for tracking changes in shell geometry, including the process of building and operating an object. In this way, it was shown that the behavior of the object depends not only on the design geometry of the shell but also on the technology of lay- 
ing the backfill. Based on the characteristic deformation of the shell, included in the function $\mathrm{f}$ $(t)$, changes in bending moments - the main component of normal stress, are forecast. During service life in A-type coatings, the bending function $\mathrm{f}(\mathrm{t})$ is reduced, which is favorable for the operation of the shell in the facility. In objects of type $B$, the function $\mathrm{f}(\mathrm{t})$ bending moment increases with time and its predicted change can be estimated after the construction is completed. On this basis, a decision can be made to monitor the facility.

In the example of the geometry of the A-type object, analyzed in [8], already at the stage of construction completion, it turned out that it belongs to group B. From the form of the $\mathrm{f}(\mathrm{t})$ function, the lack of its stabilization is visible, so the object was monitored [8]. Examples of unique objects are presented in Figures $\mathbf{1}$ and 2. They were selected from the overwhelming number of well-functioning bridge structures. The examples given in the paper are to indicate the need for monitoring bridge structures also in the phase of their operation.

\section{Source materials}

[1] Bayoglu Flaner E.: Full-scale testing of two corrugated steel box culverts with different crown stiffness. TRITA-BKN report 93. Department for Architectural and Civil Engineering, KTH, Stockholm 2006.

[2] Inaudi D.: Overview of 40 Bridge Structural Health Monitoring Projects, International Bridge Conference IBC 2010, June 15-17 2009 Pittsburgh, USA

[3] Korusiewicz.: Verification of the method of estimating bending moments in soil-steel structures on the basis of shell deformation. Weryfikacja metody szacowania momentów zginających w obiektach gruntowo-powłokowych na podstawie deformacji powłoki. Roads and Bridges - Drogi I Mosty, 15, 3, 2016, s. 221-230.

[4] Machelski C.: Badania mostowych obiektów gruntowo-powłokowych. Dolnośląskie Wydawnictwo Edukacyjne. Wrocław 2020. (w druku)

[5] Machelski C.: Klasyfikacja obiektów gruntowo-powłokowych z uwagi na zmiany deformacji podczas budowy. Przegląd Komunikacyjny 9/2016 s. 5-10.

[6] Machelski C.: The efects of dead loads in cantiliver concreting bridges. Reologiczne efekty stanu montażowego w mostach budowanych z zastosowaniem technologii nawisowej. Road and Bridge - Drogi i Mosty. 3/2019 p. 109-120.

[7] Madaj A., Sturzbecher K. Change in stress level in corrugated steel structure under long-term loads. Archives of Institute of Civil Engineering No 122012 pp. 175-184

[8] Michalski J.B., Michalski B.: Symmetry in soil-steel bridges. Archives of Institute of Civil Engineering No 122012 pp. 205-216.

[9] Takacs P.F.: Deflections in Concrete Cantilever Bridges: Observation and Theoretical Modeling. Doctoral Thesis 2002, Trondheim, Norwegia.

[10] Vaslestad J.: Long-term behavior of flexible large-span culverts. Conf. Transportation Research Board, Washington DC 1990, Record 1321 pp. 12-14 